\title{
The role of Cbln1 on Purkinje cell synapse formation
}

\author{
Aya Ito-Ishida ${ }^{1,2,3}$, Shigeo Okabe ${ }^{1}$, Michisuke Yuzaki ${ }^{2}$ \\ ${ }^{1}$ Department of Cellular Neurobiology, Graduate School of Medicine, University of \\ Tokyo, Tokyo 113-0033, Japan; ${ }^{2}$ Department of Physiology, School of Medicine, \\ Keio University, Tokyo 160-8582, Japan; ${ }^{3}$ Present address, Department of \\ Molecular and Human Genetics, Baylor College of Medicine, Houston, TX 77030, \\ U.S.A..
}

\section{Correspondence:}

Aya Ito-Ishida

+1-713-494-0167, aitou-tky@umin.ac.jp,

1250 Moursund St., Ste. 1350, Houston, TX 77030, U.S.A.

Abbreviations: Parallel fiber (PF), Molecular layer interneuron (MLI), Glutamate receptor delta 2 (GluD2), Neurexin (Nrx), Src-family kinase (SFK), $\gamma$-aminobutyric acid (GABA) 


\begin{abstract}
Cbln1 is a glycoprotein which belongs to the C1q family. In the cerebellum, Cbln1 is produced and secreted from granule cells and works as a strong synapse organizer between Purkinje cells and parallel fibers, the axons of the granule cells. In this update article, we will describe the molecular mechanisms by which Cbln1 induces synapse formation and will review our findings on the axonal structural changes which occur specifically during this process. We will also describe our recent finding that Cbln1 has a suppressive role in inhibitory synapse formation between Purkinje cells and molecular layer interneurons. Our results have revealed that Cbln1 plays an essential role to establish parallel fiber-Purkinje cell synapses and to regulate balance between excitatory and inhibitory input on Purkinje cells.
\end{abstract}

Keywords: cerebellum; Purkinje cell; synapse formation; Cbln1 


\section{Introduction}

The brain circuitry consists of millions of neurons of diverse types that communicate with each other through synapses. During development, functional circuitry is established through multiple steps (Goda and Davis, 2003). First, each neuron has to find its proper partner to establish synaptic connections, which is orchestrated by the “synapse organizers" (Fox and Umemori, 2006, Yuzaki, 2011). Synapse organizers include transmembrane proteins such as Neurexin (NRX)/neuroligin (Chih et al., 2005), leucine-rich repeat transmembrane neuronal proteins (Linhoff et al., 2009), synaptic cell-adhesion molecule (Biederer et al., 2002), cadherin family proteins (Takeichi, 2007) and EphB/ephrinB (Kayser et al., 2006), and secretory proteins such as Wnt-7a (Hall et al., 2000), fibroblast growth factors (Hall et al., 2000), and neuronal pentraxins (Xu et al., 2003). Most of these proteins are expressed specifically on presynaptic or postsynaptic sites and their interaction mediates cell type-specific intercellular interactions which determine whether excitatory or inhibitory synapses are formed. As the number of synapses increases, neuronal activity has to be controlled to maintain balance and prevent cells from being damaged by too much excitation. This requires maintaining an appropriate ratio of excitatory and inhibitory synapses (Lu et al., 2009, Levinson and El-Husseini, 2005). Finally, immature connections need to be structurally 
and functionally refined by neuronal activity to establish a mature circuitry (Sanes and Lichtman, 1999, Kano and Hashimoto, 2009, Katz and Shatz, 1996). Studying the mechanisms by which each of these steps takes place is critical to understanding the development of the brain.

The cerebellar cortex consists of relatively simple circuits, which makes it an ideal system to study how neuronal connections are formed (Eccles, 1967, De Zeeuw et al., 2011). The only cell type which sends output from the cerebellar cortex is the Purkinje cell (Figure 1A). Purkinje cells expand their vast dendritic arbors in the cerebellar molecular layer, where they receive excitatory input from the parallel fibers (PFs: granule cells' axons) and the climbing fibers (axons from inferior olive neurons), and inhibitory input from the molecular layer interneurons (MLIs). Excitatory synapses formed between the Purkinje cells and PFs comprise the highest number of synapses in the brain. Each Purkinje cell forms 100,000 - 200,000 synapses with the PFs in rodents (Harvey and Napper, 1991); proper function of these synapses is essential for motor coordination and learning (Ito, 2002).

Cbln1 is a synapse organizer that is indispensable for the formation and maintenance of PF-Purkinje cell synapses in vivo (Hirai et al., 2005, Ito-Ishida et al., 2008). In this review, we will describe multiple aspects of Cbln1's role on Purkinje cells' synapse 
development. We will describe how Cbln1 mediates structural and functional maturation of PF terminals. We will also give an update on our recent findings of Cbln1's role on MLI-Purkinje cell synapse function. These findings suggest that Cbln1 plays an important role in orchestrating excitatory and inhibitory synapse formation in Purkinje cells.

\section{Cbln1 induces PF-Purkinje cell synapse formation in vivo}

Cbln1 is a secretory glycoprotein produced in the cerebellar granule cells (Hirai et al., 2005). It belongs to the C1q family along with other proteins such as C1q, which is part of the complement cascade, and adiponectin (Yuzaki, 2011). Cbln1 was first identified as a precursor of cerebellin, which was found biochemically as a polypeptide specifically enriched in the synaptosomal fraction of the mouse cerebellum (Urade et al., 1991). Studies of mice genetically lacking Cbln1 (cbln1-null mice) have revealed a crucial role for full-length Cbln1 in cerebellar function (Hirai et al., 2005), as cbln1-null mice show severe ataxia due to a significant reduction of PF-Purkinje cell synapses. We have further demonstrated this importance by rescue experiments using recombinant Cbln1 (Ito-Ishida et al., 2008). When recombinant Cbln1 was injected into the subarachnoidal supracerebellar space of cbln1-null mice, normal densities of 
PF-Purkinje cell synapses were restored within 2 days, together with remarkable improvement of motor dysfunction. However, the effect did not last long. As the recombinant Cbln1 was degraded, the established synapses were lost and ataxia recurred 1 week after the injection, revealing that Cbln 1 is also required for the maintenance of the synapses. Because many other synapse organizers identified in vitro are not essential for the formation of excitatory synapses in vivo (Dudanova et al., 2007, Missler et al., 2003, Varoqueaux et al., 2006), Cbln1 may be considered as a uniquely strong synapse organizer (Ito-Ishida et al., 2008, Hirai et al., 2005).

Recent studies identified postsynaptic and presynaptic receptors for Cbln1 as glutamate receptor delta 2 (GluD2) and Nrx (Figure 1B) (Uemura et al., 2010, Matsuda et al., 2010, Matsuda and Yuzaki, 2011). GluD2 is a transmembrane protein specifically expressed in the Purkinje cells' spines. Although it was classified as an ionotropic glutamate receptor based on its amino acid sequence, it did not show any glutamate-induced channel activity and its ligand has been a mystery (Kakegawa et al., 2007). When the phenotype of cbln1-null mice was characterized, it was strikingly similar to that of mice lacking GluD2 (glud2-null mice). They both showed severe ataxia due to the specific loss of PF-Purkinje cell synapses and had abnormal Purkinje cell spine structures such as "naked spines", with no presynaptic endings, and 
"mismatched spines", which had long PSDs that did not match the length of active zones (Kashiwabuchi et al., 1995, Hirai et al., 2005, Kurihara et al., 1997). These findings suggested that Cbln1 and GluD2 share a common signaling pathway. Indeed, it was found that Cbln1 directly interacts with the $\mathrm{N}$-terminal extracellular domain of GluD2, and that GluD2 is indispensable for Cbln1-induced synapse formation (Matsuda et al., 2010, Uemura et al., 2010). Cbln1 and GluD2, together with presynaptic Nrx, were shown to form a tripartite complex that functions to maintain the connection between PF terminals and Purkinje cells' spines (Matsuda and Yuzaki, 2011, Sotelo, 1990). The Nrx-Cbln1-GluD2 tripartite complex works ideally to promote bidirectional differentiation of the presynaptic and postsynaptic components. When Cbln1 binds to GluD2, it promotes clustering of GluD2 in the spine, while GluD2's C-terminus intracellular domain recruits several scaffold proteins which may promote maturation of the postsynaptic sites (Uemura et al., 2004, Matsuda et al., 2010). At the same time, binding of Cbln1 to Nrx promotes clustering of Nrx at the presynaptic site, which promotes accumulation of active zone proteins and synaptic vesicles (Uemura et al., 2010, Matsuda and Yuzaki, 2011). Because Cbln1 is a hexamer and GluD2 is a tetramer, the large size of the in vivo Nrx-Cbln1-GluD2 complex may further promote accumulation of the synaptic components through a positive-feedback mechanism (Lee 
et al., 2012, Matsuda and Yuzaki, 2011).

\section{Cbln1 induces dynamic structural changes in PFs during synapse formation}

Synapse formation occurs in multiple steps. First, axonal terminals and dendrites make contacts. Second, pre- and postsynaptic structures are induced. Lastly, maturation takes place and nascent synapses become functional (Goda and Davis, 2003). This step-by-step process has been difficult to clarify because synapse formation occurs randomly and gradually. Most previous studies have focused on how dendritic spines are formed in hippocampal and cortical excitatory neurons and have led to the following two models that describe the process (Yuste and Bonhoeffer, 2004). In the "filopodial model", dendritic filopodia capture axonal terminals and induce presynaptic differentiation (Okabe et al., 2001, Knott et al., 2006, Ziv and Smith, 1996). The interaction between the dendritic filopodia and the axons further promotes maturation of mushroom-shaped spines. In the "Millier/Peters model", axonal terminals play a key role in initiating synapse formation and converting preexisting shaft synapses to spine synapses (Harris, 1999, Yuste and Bonhoeffer, 2004, Miller and Peters, 1981). In these models, interaction between axons and dendrites is essential for spine formation. In contrast, it has been known that Purkinje cells' spines are formed autonomously in the 
absence of axonal input (Sotelo, 1990). Even in mice without any granule cells (weaver or reeler mice), Purkinje cells grow numerous "naked spines" that have no presynaptic structures (Sotelo, 1990). Naked spines are also observed in glud2-null and cbln1-null mice whose PF-Purkinje cell synapses are significantly reduced (Kurihara et al., 1997, Hirai et al., 2005). Furthermore, an early study showed the existence of naked spines in the wild-type immature cerebellum (Larramendi, 1969). These findings indicated that Purkinje cell spines are formed prior to the formation of PF terminals. However, how the presynaptic structure differentiates to form functional synapses remained unknown.

In order to clarify how PF terminals differentiate during synapse development, we took advantage of the synapse-inducing effect of Cbln1 (Ito-Ishida et al., 2012). We visualized PFs and Purkinje cells at the same time by labeling each cell type with different fluorescent proteins. Synapse formation was induced by applying recombinant Cbln1 to cerebellar slice cultures from $c b \ln 1$-null mice, and we observed the entire process of synapse formation by live-imaging. Our results revealed that Cbln1, via its interaction with Nrx and GluD2, induces PF protrusions to promote differentiation of the presynaptic and postsynaptic structures (Figure 2). Existence of PF protrusions in the immature cerebellum of wild-type mice was confirmed in vivo by electron microscopy. To analyze the physiological significance of these PF protrusions, we 
visualized synaptic vesicles and GluD2 by live-imaging and found that PF structural changes are associated with accumulation of these synaptic components. Taken together, we concluded that Purkinje cell synapse formation may be described by the "bidirectional interaction model", in which the process occurs in 5 steps (Figure 2): First, as proposed by the Sotelo model, Purkinje cell spines are formed autonomously independent of PF input (Figure 2A). Second, PFs and Purkinje cell spines make contacts and Cbln1-GluD2 interaction is initiated, which triggers accumulation of Nrx and synaptic vesicles at the future presynaptic sites (Figure 2B). Third, Cbln1-Nrx interaction activates actin cytoskeleton rearrangement in PFs, leading to the formation of axonal protrusions (Figure 2C). The protrusions dynamically change shapes and occasionally encapsulate Purkinje cell spines (Figure 2D). Fourth, transient coverage of the spines by PF protrusions increase the contact made between PFs and the spines, which further enhances Nrx-Cbln1-GluD2 interaction by a positive-feedback mechanism. Finally, the protrusive membrane retracts and a mature PF-Purkinje cell synapse is formed (Figure 2E).

Although existence of the encapsulated spines in Purkinje cells had been suggested by early ultrastructural studies of immature cerebellum, their physiological significance remained unknown (Altman and Bayer, 1996). Our findings revealed their potential 
importance for the maturation of synapses (Ito-Ishida et al., 2012). It is likely that decreased diffusion of glutamate within the synaptic cleft promotes excitatory transmission at these synapses. Further study is necessary to clarify electrophysiological properties of the encapsulated synapses.

\section{Cbln1 regulates MLI-Purkinje cell synapse development through inhibition of}

\section{Src-family kinase}

In addition to the two excitatory inputs from PFs and climbing fibers, Purkinje cells receive inhibitory inputs from MLIs, which consist of basket cells and stellate cells (De Zeeuw et al., 2011, Wulff et al., 2009) (Fig. 1). PFs send excitatory output to MLIs as well as Purkinje cells, while MLIs inhibit Purkinje cells. This feed-forward circuitry is shown to be important to phase-lock PF-induced excitation of the Purkinje cells and to be indispensable for cerebellum-dependent motor learning (Wulff et al., 2009). However, despite its physiological importance, molecular mechanisms that modify the formation and the function of MLI-Purkinje cell synapses remain largely unknown.

Recently, we found that Cbln1 has a suppressive role on MLI-Purkinje cell synapse formation and function (Ito-Ishida, 2014). We analyzed MLI-Purkinje cell synapses in cbln1-null mice and found that the density of MLI-inhibitory synapses is increased 
compared to wild-type mice (Figure 3A). Electrophysiological recordings revealed that the miniature inhibitory postsynaptic current (mIPSC) of Purkinje cells in cblnl-null mice had increased amplitude and frequency. Interestingly, these structural and functional abnormalities were restored by recombinant Cbln1 but at different effective periods. Reversal of mIPSC amplitude in cbln1-null Purkinje cells required a 3-hour incubation of recombinant Cbln1. In contrast, Cbln1 had to be present a few days to restore the inhibitory synapse density. We also found that the effect of Cbln 1 depends on GluD2, which is expressed preferentially on the excitatory postsynaptic sites. Because Cbln1-GluD2 signaling occurs mainly at the excitatory PF synapses, we reasoned that there must be an intracellular protein that can travel through the dendrite- to mediate heterosynaptic modulation of inhibitory synapses between MLIs and Purkinje cells. Src-family tyrosine kinase (SFK) was a likely candidate because previous studies indicated that SFKs enhance mIPSCs in Purkinje cells (Boxall, 2000). In addition, SFKs are reported to phosphorylate $\beta$ and $\gamma$ subunits of $\gamma$-aminobutyric acid (GABA)-A receptors and to increase the GABA-mediated current (Moss et al., 1995, Valenzuela et al., 1995, Wan et al., 1997, Jurd et al., 2010). Phosphorylation of the $\gamma 2$ subunits of GABA-A receptors in the intracellular region is also reported to suppress clathrin-mediated endocytosis and to increase the surface expression of the GABA-A 
receptor (Kittler et al., 2008). Furthermore, we recently found that the tyrosine phosphorylation level is increased in glud2-null cerebellum (Kohda et al., 2013). Taken together, we hypothesized that Cbln1-GluD2 signaling inhibits SFK activity in the spines, which may propagate through the dendrite to suppress MLI synaptic function (Figure 3B). Supporting this hypothesis, we showed that PF-evoked slow excitatory postsynaptic currents (slowEPSCs), which reflect the tyrosine phosphorylation level of Purkinje cells (Canepari and Ogden, 2003), was reduced in cblnl-null Purkinje cells. The reduced ${ }_{\text {slow }}$ EPSC amplitudes were rescued by introducing a PP1 analog, which is a specific SFK inhibitor, using a patch pipette. Similarly, increased mIPSC amplitude was reversed by a PP1 analog (Ito-Ishida, 2014). The intracellular domain of GluD2 has been shown to interact with megakaryocyte protein tyrosine phosphatase (PTPMEG), which inhibits SFK activity (Hironaka et al., 2000). Therefore, we speculate that Cbln1-GluD2 signaling promotes accumulation of GluD2 and PTPMEG at the spine, which results in PTPMEG activation and inhibition of SFK activity, leading to the decrease in mIPSC amplitude (Figure 3B).

During development, PF-Purkinje cell synapse formation promotes elimination of redundant climbing fiber terminals (Kano and Hashimoto, 2009). Robust reduction in PF synapses in $c b \ln 1$-null and glud2-null mice leads to abnormal synapse elimination 
and persistent multiple innervation by the climbing fibers (Hirai et al., 2005, Hashimoto et al., 2001). Similarly to the effect of PFs on climbing fibers, we found that Cbln1-induced PF-Purkinje cell synapse formation may be important to sculpt inhibitory synapses between MLIs and Purkinje cells (Ito-Ishida, 2014). In mature cerebellum, MLI-Purkinje cell synapses are more abundant in the proximal dendrite of the Purkinje cells while PFs are much denser in the distal areas. PF-mediated suppression of MLI terminals may be essential to establish regional innervation patterns of these terminals onto the Purkinje cells (Figure 3A).

\section{Future perspectives}

Through our work on the role of Cbln1, we have reached three conclusions: 1 . Cbln1 is a strong inducer of PF-Purkinje cell synapse formation in vivo through interactions with Nrx and GluD2 (Ito-Ishida et al., 2008, Matsuda et al., 2010, Matsuda and Yuzaki, 2011, Uemura et al., 2010). 2. PFs extend protrusions that promote synapse maturation during the synaptogenesis (Ito-Ishida et al., 2012). 3. Cbln1 down-regulates inhibitory synapse formation and function on Purkinje cells (Ito-Ishida, 2014). Taking advantage of Cbln1's effect, we are now able to switch on and off the connections between PFs and Purkinje cells. This property may be utilized to study how 
PF-Purkinje cell synapses are involved in learning and memory. Recently, we used this system and revealed that PF-Purkinje cell synapses are necessary for the establishment but not storage of associative learning in the cerebellum (Emi et al., 2013). Because Cbln1 has other family members that are expressed outside of the cerebellum, it would be interesting to test whether Nrx-Cbln-GluD signaling operates in other areas to modify synapse structures (Iijima et al., 2007, Miura et al., 2006). Our discovery of the existence of PF protrusions during synaptogenesis raises many questions that remain to be addressed. What is the molecular mechanism that promotes structural changes down-stream of Nrx? How are they modulated by neuronal activity? What is the correlation between PF protrusion formation and glial coverage of the synapses? Much less is known about MLI-Purkinje cell synapse formation. It would be essential to characterize which synapse components are expressed specifically in Purkinje cells, granule cells, and MLIs. Knowledge gained through such experiments will clarify the mechanisms by which specific cell partners establish specific types of synapses and will give us an insight into hierarchical relationships between multiple kinds of synapse organizers. 


\section{Acknowledgement}

This research has been supported by the Core Research for Evolutional Science and

Technology from the Japan Science and Technology Agency (M.Y.), and Grants-in-Aid for Scientific Research (KAKENHI) from the Ministry of Education, Culture, Sports,

Science and Technology of Japan (A.I-I., S.O., and M.Y.). We would like to thank Dr.

Kerstin Ure (Baylor College of Medicine) for discussion and critical comments on the manuscript.

\section{References}

Altman, A. \& Bayer, S. A. 1996. Early synaptogenesis and the development of parallel fiber synapses with Purkinje cells. Development of the cerebellar system: in relation to its evolution, structure, and functions. Boca Raton, FL: CRC press.

Biederer, T., Sara, Y., Mozhayeva, M., Atasoy, D., Liu, X., Kavalali, E. T. \& Sudhof, T. C. 2002. SynCAM, a synaptic adhesion molecule that drives synapse assembly. Science, 297, 1525-31.

Boxall, A. R. 2000. GABAergic mIPSCs in rat cerebellar Purkinje cells are modulated by TrkB and mGluR1-mediated stimulation of Src. J Physiol, 524 Pt 3, 677-84.

Canepari, M. \& Ogden, D. 2003. Evidence for protein tyrosine phosphatase, tyrosine kinase, and G-protein regulation of the parallel fiber metabotropic slow EPSC of rat cerebellar Purkinje neurons. J Neurosci, 23, 4066-71.

Chih, B., Engelman, H. \& Scheiffele, P. 2005. Control of excitatory and inhibitory synapse formation by neuroligins. Science, 307, 1324-8.

De Zeeuw, C. I., Hoebeek, F. E., Bosman, L. W., Schonewille, M., Witter, L. \& Koekkoek, S. K. 2011. Spatiotemporal firing patterns in the cerebellum. Nat Rev Neurosci, 12, 327-44. 
Dudanova, I., Tabuchi, K., Rohlmann, A., Südhof, T. C. \& Missler, M. 2007. Deletion of $\alpha$-neurexins does not cause a major impairment of axonal pathfinding or synapse formation. The Journal of Comparative Neurology, 502, 261-274.

Eccles, J. C. 1967. Circuits in the cerebellar control of movement. Proc Natl Acad Sci U $S A, 58,336-43$.

Emi, K., Kakegawa, W., Miura, E., Ito-Ishida, A., Kohda, K. \& Yuzaki, M. 2013. Reevaluation of the role of parallel fiber synapses in delay eyeblink conditioning in mice using Cbln1 as a tool. Frontiers in Neural Circuits, 7.

Fox, M. A. \& Umemori, H. 2006. Seeking long-term relationship: axon and target communicate to organize synaptic differentiation. J Neurochem, 97, 1215-31.

Goda, Y. \& Davis, G. W. 2003. Mechanisms of synapse assembly and disassembly. Neuron, 40, 243-64.

Hall, A. C., Lucas, F. R. \& Salinas, P. C. 2000. Axonal remodeling and synaptic differentiation in the cerebellum is regulated by WNT-7a signaling. Cell, 100, 525-35.

Harris, K. M. 1999. Structure, development, and plasticity of dendritic spines. Curr Opin Neurobiol, 9, 343-8.

Harvey, R. J. \& Napper, R. M. 1991. Quantitative studies on the mammalian cerebellum. Prog Neurobiol, 36, 437-63.

Hashimoto, K., Ichikawa, R., Takechi, H., Inoue, Y., Aiba, A., Sakimura, K., Mishina, M., Hashikawa, T., Konnerth, A., Watanabe, M. \& Kano, M. 2001. Roles of glutamate receptor delta 2 subunit (GluRdelta 2) and metabotropic glutamate receptor subtype 1 (mGluR1) in climbing fiber synapse elimination during postnatal cerebellar development. J Neurosci, 21, 9701-12.

Hirai, H., Pang, Z., Bao, D., Miyazaki, T., Li, L., Miura, E., Parris, J., Rong, Y., Watanabe, M., Yuzaki, M. \& Morgan, J. I. 2005. Cbln1 is essential for synaptic integrity and plasticity in the cerebellum. Nat Neurosci, 8, 1534-41.

Hironaka, K., Umemori, H., Tezuka, T., Mishina, M. \& Yamamoto, T. 2000. The protein-tyrosine phosphatase PTPMEG interacts with glutamate receptor delta 2 and epsilon subunits. J Biol Chem, 275, 16167-73.

Iijima, T., Miura, E., Matsuda, K., Kamekawa, Y., Watanabe, M. \& Yuzaki, M. 2007. Characterization of a transneuronal cytokine family Cbln--regulation of secretion by heteromeric assembly. Eur J Neurosci, 25, 1049-57.

Ito-Ishida, A., Miura, E., Emi, K., Matsuda, K., Iijima, T., Kondo, T., Kohda, K., Watanabe, M. \& Yuzaki, M. 2008. Cbln1 regulates rapid formation and maintenance of excitatory synapses in mature cerebellar Purkinje cells in vitro 
and in vivo. $J$ Neurosci, 28, 5920-30.

Ito-Ishida, A., Miyazaki, T., Miura, E., Matsuda, K., Watanabe, M., Yuzaki, M. \& Okabe, S. 2012. Presynaptically released Cbln1 induces dynamic axonal structural changes by interacting with GluD2 during cerebellar synapse formation. Neuron, 76, 549-64.

Ito-Ishida, A., W. Kakegawa, K. Kohda, K. E. Miura, S. Okabe \& M.Yuzaki 2014. Cbln1 down-regulates the formation and function of inhibitory synapses in mouse cerebellar Purkinje cells. Eur J Neurosci, in press.

Ito, M. 2002. The molecular organization of cerebellar long-term depression. Nat Rev Neurosci, 3, 896-902.

Jurd, R., Tretter, V., Walker, J., Brandon, N. J. \& Moss, S. J. 2010. Fyn kinase contributes to tyrosine phosphorylation of the $\mathrm{GABA}(\mathrm{A})$ receptor gamma2 subunit. Mol Cell Neurosci, 44, 129-34.

Kakegawa, W., Kohda, K. \& Yuzaki, M. 2007. The delta2 'ionotropic' glutamate receptor functions as a non-ionotropic receptor to control cerebellar synaptic plasticity. J Physiol, 584, 89-96.

Kano, M. \& Hashimoto, K. 2009. Synapse elimination in the central nervous system. Current Opinion in Neurobiology, 19, 154-161.

Kashiwabuchi, N., Ikeda, K., Araki, K., Hirano, T., Shibuki, K., Takayama, C., Inoue, Y., Kutsuwada, T., Yagi, T., Kang, Y. \& Et Al. 1995. Impairment of motor coordination, Purkinje cell synapse formation, and cerebellar long-term depression in GluR delta 2 mutant mice. Cell, 81, 245-52.

Katz, L. C. \& Shatz, C. J. 1996. Synaptic activity and the construction of cortical circuits. Science, 274, 1133-8.

Kayser, M. S., Mcclelland, A. C., Hughes, E. G. \& Dalva, M. B. 2006. Intracellular and trans-synaptic regulation of glutamatergic synaptogenesis by EphB receptors. $J$ Neurosci, 26, 12152-64.

Kittler, J. T., Chen, G., Kukhtina, V., Vahedi-Faridi, A., Gu, Z., Tretter, V., Smith, K. R., Mcainsh, K., Arancibia-Carcamo, I. L., Saenger, W., Haucke, V., Yan, Z. \& Moss, S. J. 2008. Regulation of synaptic inhibition by phospho-dependent binding of the AP2 complex to a YECL motif in the GABAA receptor gamma2 subunit. Proc Natl Acad Sci U S A, 105, 3616-21.

Knott, G. W., Holtmaat, A., Wilbrecht, L., Welker, E. \& Svoboda, K. 2006. Spine growth precedes synapse formation in the adult neocortex in vivo. Nat Neurosci, 9, 1117-24.

Kohda, K., Kakegawa, W., Matsuda, S., Yamamoto, T., Hirano, H. \& Yuzaki, M. 2013. 
The delta2 glutamate receptor gates long-term depression by coordinating interactions between two AMPA receptor phosphorylation sites. Proc Natl Acad Sci U S A, 110, E948-57.

Kurihara, H., Hashimoto, K., Kano, M., Takayama, C., Sakimura, K., Mishina, M., Inoue, Y. \& Watanabe, M. 1997. Impaired parallel fiber-->Purkinje cell synapse stabilization during cerebellar development of mutant mice lacking the glutamate receptor delta2 subunit. J Neurosci, 17, 9613-23.

Larramendi, L. M. H. 1969. Analysis of synaptogenesis in the cerebellum of the mouse. In: LLIN S, R. (ed.) Neurobiology of Cerebellar Evolution and Development. Chicago: American Medical Association Education and Research foundation.

Lee, S. J., Uemura, T., Yoshida, T. \& Mishina, M. 2012. GluRdelta2 assembles four neurexins into trans-synaptic triad to trigger synapse formation. J Neurosci, 32, 4688-701.

Levinson, J. N. \& El-Husseini, A. 2005. Building excitatory and inhibitory synapses: balancing neuroligin partnerships. Neuron, 48, 171-4.

Linhoff, M. W., Lauren, J., Cassidy, R. M., Dobie, F. A., Takahashi, H., Nygaard, H. B., Airaksinen, M. S., Strittmatter, S. M. \& Craig, A. M. 2009. An unbiased expression screen for synaptogenic proteins identifies the LRRTM protein family as synaptic organizers. Neuron, 61, 734-49.

Lu, B., Wang, K. H. \& Nose, A. 2009. Molecular mechanisms underlying neural circuit formation. Current Opinion in Neurobiology, 19, 162-167.

Matsuda, K., Miura, E., Miyazaki, T., Kakegawa, W., Emi, K., Narumi, S., Fukazawa, Y., Ito-Ishida, A., Kondo, T., Shigemoto, R., Watanabe, M. \& Yuzaki, M. 2010. Cbln1 is a ligand for an orphan glutamate receptor delta2, a bidirectional synapse organizer. Science, 328, 363-8.

Matsuda, K. \& Yuzaki, M. 2011. Cbln family proteins promote synapse formation by regulating distinct neurexin signaling pathways in various brain regions. Eur $J$ Neurosci, 33, 1447-61.

Miller, M. \& Peters, A. 1981. Maturation of rat visual cortex. II. A combined Golgi-electron microscope study of pyramidal neurons. J Comp Neurol, 203, 555-73.

Missler, M., Zhang, W., Rohlmann, A., Kattenstroth, G., Hammer, R. E., Gottmann, K. \& Sudhof, T. C. 2003. [alpha]-Neurexins couple Ca2+ channels to synaptic vesicle exocytosis. Nature, 423, 939-948.

Miura, E., Iijima, T., Yuzaki, M. \& Watanabe, M. 2006. Distinct expression of Cbln family mRNAs in developing and adult mouse brains. Eur J Neurosci, 24, 
750-60.

Moss, S. J., Gorrie, G. H., Amato, A. \& Smart, T. G. 1995. Modulation of GABAA receptors by tyrosine phosphorylation. Nature, 377, 344-8.

Okabe, S., Miwa, A. \& Okado, H. 2001. Spine formation and correlated assembly of presynaptic and postsynaptic molecules. J Neurosci, 21, 6105-14.

Sanes, J. R. \& Lichtman, J. W. 1999. Development of the vertebrate neuromuscular junction. Annu Rev Neurosci, 22, 389-442.

Sotelo, C. 1990. Cerebellar synaptogenesis: what we can learn from mutant mice. $J$ Exp Biol, 153, 225-49.

Takeichi, M. 2007. The cadherin superfamily in neuronal connections and interactions. Nat Rev Neurosci, 8, 11-20.

Uemura, T., Lee, S. J., Yasumura, M., Takeuchi, T., Yoshida, T., Ra, M., Taguchi, R., Sakimura, K. \& Mishina, M. 2010. Trans-synaptic interaction of GluRdelta2 and Neurexin through Cbln1 mediates synapse formation in the cerebellum. Cell, 141, 1068-79.

Uemura, T., Mori, H. \& Mishina, M. 2004. Direct interaction of GluRdelta2 with Shank scaffold proteins in cerebellar Purkinje cells. Mol Cell Neurosci, 26, 330-41.

Urade, Y., Oberdick, J., Molinar-Rode, R. \& Morgan, J. I. 1991. Precerebellin is a cerebellum-specific protein with similarity to the globular domain of complement C1q B chain. Proc Natl Acad Sci U S A, 88, 1069-73.

Valenzuela, C. F., Machu, T. K., Mckernan, R. M., Whiting, P., Vanrenterghem, B. B., Mcmanaman, J. L., Brozowski, S. J., Smith, G. B., Olsen, R. W. \& Harris, R. A. 1995. Tyrosine kinase phosphorylation of GABAA receptors. Brain Res Mol Brain Res, 31, 165-72.

Varoqueaux, F., Aramuni, G., Rawson, R. L., Mohrmann, R., Missler, M., Gottmann, K., Zhang, W., Südhof, T. C. \& Brose, N. 2006. Neuroligins Determine Synapse Maturation and Function. Neuron, 51, 741-754.

Wan, Q., Man, H. Y., Braunton, J., Wang, W., Salter, M. W., Becker, L. \& Wang, Y. T. 1997. Modulation of GABAA receptor function by tyrosine phosphorylation of beta subunits. J Neurosci, 17, 5062-9.

Wulff, P., Schonewille, M., Renzi, M., Viltono, L., Sassoe-Pognetto, M., Badura, A., Gao, Z., Hoebeek, F. E., Van Dorp, S., Wisden, W., Farrant, M. \& De Zeeuw, C. I. 2009. Synaptic inhibition of Purkinje cells mediates consolidation of vestibulo-cerebellar motor learning. Nat Neurosci, 12, 1042-9.

Xu, D., Hopf, C., Reddy, R., Cho, R. W., Guo, L., Lanahan, A., Petralia, R. S., Wenthold, R. J., O'brien, R. J. \& Worley, P. 2003. Narp and NP1 form heterocomplexes that 
function in developmental and activity-dependent synaptic plasticity. Neuron, 39, 513-28.

Yuste, R. \& Bonhoeffer, T. 2004. Genesis of dendritic spines: insights from ultrastructural and imaging studies. Nat Rev Neurosci, 5, 24-34.

Yuzaki, M. 2011. Cbln1 and its family proteins in synapse formation and maintenance. Curr Opin Neurobiol, 21, 215-20.

Ziv, N. E. \& Smith, S. J. 1996. Evidence for a role of dendritic filopodia in synaptogenesis and spine formation. Neuron, 17, 91-102. 


\section{Figure Captions}

\section{Figure 1}

Synapses on Purkinje cells and Cbln1

(A) Synaptic inputs onto the Purkinje cells. Purkinje cells receive excitatory synapses from PFs and climbing fibers, and inhibitory synapses from two kinds of interneurons, stellate cells and basket cells.

(B) Cbln1 forms a tripartite protein complex with Nrx and GluD2. The complex works to hold the gap between PF terminals and Purkinje cells' spines.

\section{Figure 2}

Structural changes of PFs during Cbln1-induced synapse formation

(A) Purkinje cells' spines are autonomously formed independent of PFs (Sotelo model).

(B) PFs and spines make contacts, which triggers interaction between Cbln1 and GluD2. This interaction promotes accumulation of Nrx and synaptic vesicles (SVs) at the future presynaptic sites.

(C) Nrx-Cbln1-GluD2 complex triggers actin cytoskeleton remodeling in PFs which 
induces PF protrusions.

(D) PF protrusions dynamically change shape and some protrusions encapsulate Purkinje cells' spines, which promote further accumulation of synaptic vesicles and GluD2.

(E) PF protrusions retract and mature PF boutons are formed.

\section{Figure 3}

Cbln1 down-regulates MLI-Purkinje cell synapse formation and function.

(A) Cbln1 suppresses MLI-Purkinje cell synapse formation. In wild-type mice, PF terminal density is higher in the distal dendrite of the Purkinje cells, while MLI-terminals are highest in the proximal dendrite. In $c b \ln 1$-null mice, PF terminals are reduced and MLI-synapses are increased, leading to the reduced difference in the regional distribution of excitatory and inhibitory synapses.

(B) GABA-A-mediated current is suppressed by Cbln1 through SFK (src) pathway. Cbln1 induces clustering of GluD2 in Purkinje cells' spines, which promote recruitment of PTPMEG. Activation of PTMPEG results in suppressed SFKs leading to the decrease in GABA-A surface expression level. 
Figure 1

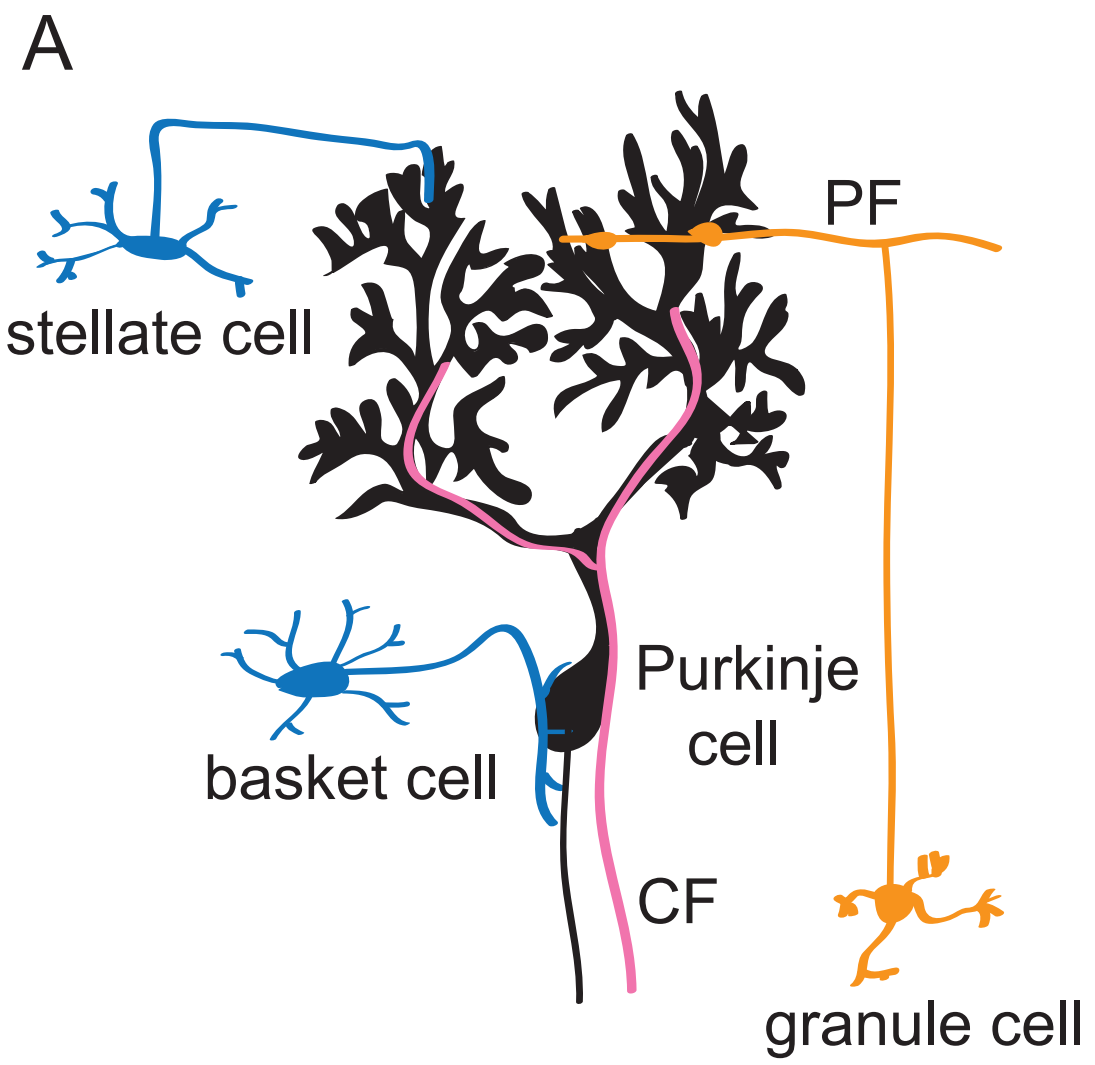

B

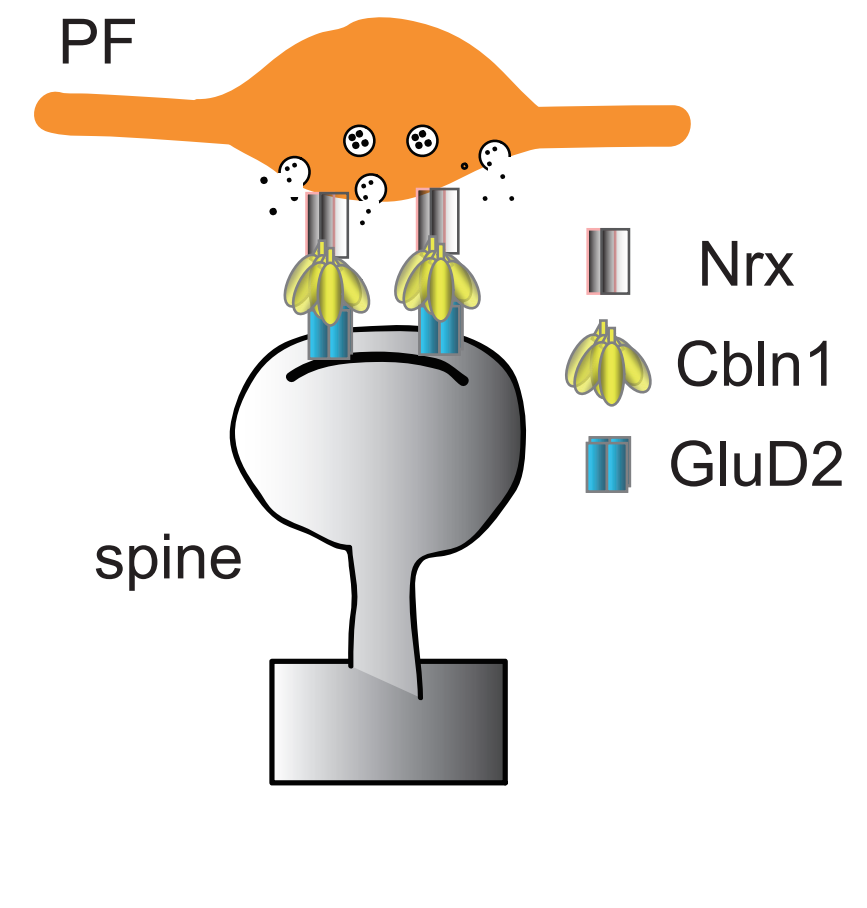




\section{Figure 2}

A

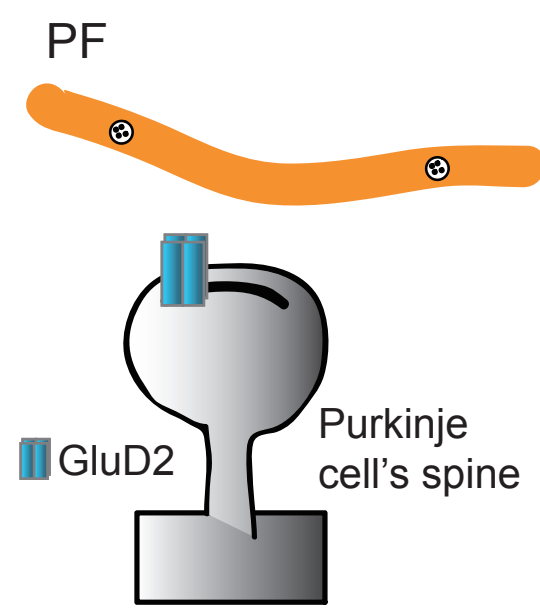

B

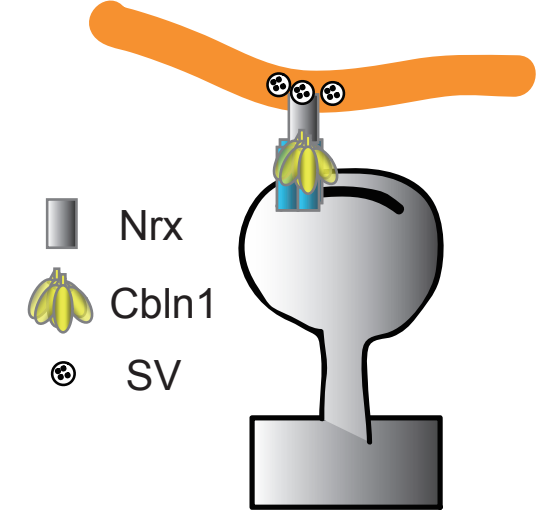

C

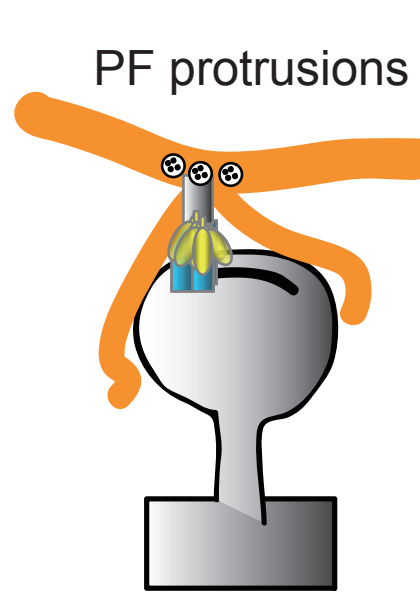

D

$$
\text { complex protrusions }
$$

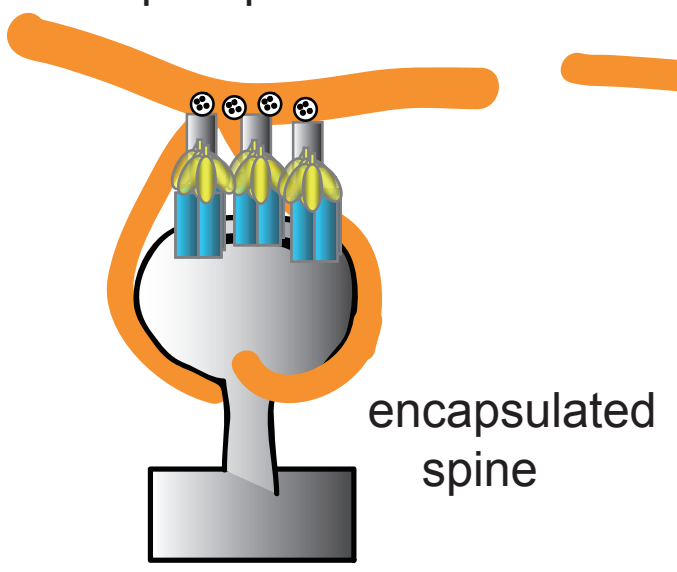

E

mature synapse

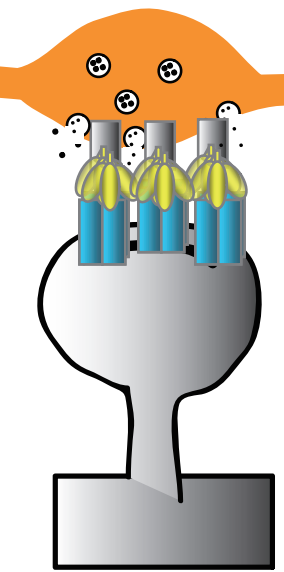


Figure 3
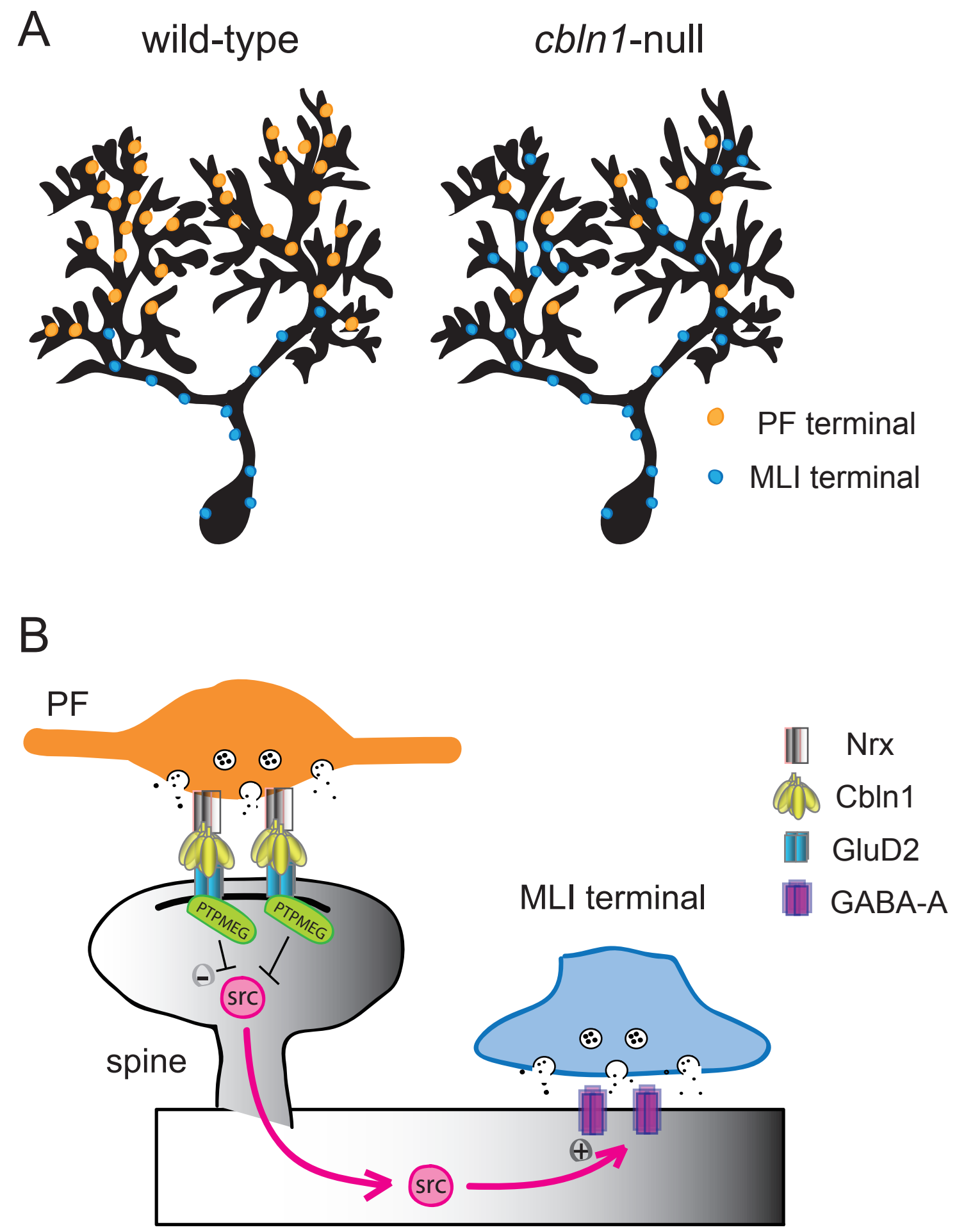